\title{
Q.
QNEEN'S
UNIVERSITY
BELFAST
}

\section{Engaging hard-to-reach populations in research on health in pregnancy: the value of Boal's simultaneous dramaturgy}

Smyth, L., McClements, L., \& Murphy, P. (2020). Engaging hard-to-reach populations in research on health in pregnancy: the value of Boal's simultaneous dramaturgy. Arts \& Health: An International Journal for Research, Policy and Practice, 12(1), 71-79. https://doi.org/10.1080/17533015.2018.1555176

Published in:

Arts \& Health: An International Journal for Research, Policy and Practice

Document Version:

Peer reviewed version

Queen's University Belfast - Research Portal:

Link to publication record in Queen's University Belfast Research Portal

Publisher rights

Copyright 2018 Informa UK Limited, trading as Taylor \& Francis Group.

This is an accepted manuscript distributed under a Creative Commons Attribution-NonCommercial-NoDerivs License

(https://creativecommons.org/licenses/by-nc-nd/4.0/), which permits distribution and reproduction for non-commercial purposes, provided the author and source are cited.

\section{General rights}

Copyright for the publications made accessible via the Queen's University Belfast Research Portal is retained by the author(s) and / or other copyright owners and it is a condition of accessing these publications that users recognise and abide by the legal requirements associated with these rights.

Take down policy

The Research Portal is Queen's institutional repository that provides access to Queen's research output. Every effort has been made to ensure that content in the Research Portal does not infringe any person's rights, or applicable UK laws. If you discover content in the Research Portal that you believe breaches copyright or violates any law, please contact openaccess@qub.ac.uk. 


\title{
Engaging hard-to-reach populations in research on health in pregnancy: the value of Boal's simultaneous dramaturgy.
}

This is an Accepted Manuscript of an article published by Taylor \& Francis in Arts \& Health, available online: http://www.tandfonline.com/.

This work is licensed under a Creative Commons Attribution-NonCommercial-ShareAlike 2.5 License.

\author{
Authors and affiliations \\ Lisa Smyth ${ }^{1}$, Lana McClements ${ }^{2}$, Paul Murphy ${ }^{3}$ \\ ${ }^{1}$ School of Social Sciences, Education and Social Work; \\ ${ }^{2}$ Centre for Experimental Medicines, School of Medicine, Dentistry and Biomedical Sciences; \\ ${ }^{3}$ Arts, English and Languages; Queen's University Belfast, UK
}

\section{Corresponding author address}

Lisa Smyth,

School of Social Sciences, Education and Social Work, Queen's University Belfast,

6 College Park, Belfast, BT7 1NN, UK

Email L.Smyth@qub.ac.uk

\begin{abstract}
Migrant populations are among the hardest to reach for research purposes. An interdisciplinary research team piloted a modified version of Boal's simultaneous dramaturgy with Roma mothers in Belfast. The technique, based on scripted scenario performances, translations, and discussions, proved helpful for engaging with this hard-to-reach population, despite low levels of literacy, high language barriers, and cultural separateness. Based on a very small number of participants, the approach suggests the persistence of attitudes to pregnancy which reinforce health inequalities, and present significant challenges for improving the health of marginalized populations. This pilot underlines the importance of building trust through holistic approaches to working with hard-to-reach populations through the creative arts.
\end{abstract}

\section{Keywords}

Health in pregnancy, hard-to-reach populations, Roma mothers, Boal, simultaneous dramaturgy.

\section{Funding}

The funding was provided by the Department for the Economy Northern Ireland, Global Challenge Research Fund award.

\section{Acknowledgements}

We would like to sincerely thank those who participated in this pilot study. We are also grateful to the Romanian Roma Community Centre in Belfast for their support with the event reported here.

\section{Conflicts of interest}

None. 
Engaging hard-to-reach populations in research on health in pregnancy: the value of Boal's simultaneous dramaturgy.

\section{Introduction: Doing research with hard-to-reach populations}

Researchers tend to find some populations hard-to-reach, largely due to the barriers presented by multiple and complex forms of deprivation (Boag-Munroe \& Evangelou, 2012). Migrants have been identified as some of the most hard-to-reach research populations, whether because of temporary living arrangements, geographic dispersal, or cultural separateness, which can be difficult to gain entry to for outsiders (Shaghaghi, Bhopal, \& Sheikh, 2011, p. 87). While the phrase 'hard-to-reach' is contested, and can be used to refer to social elites as well as more vulnerable populations (EllardGray, Jeffrey, Choubak, \& Crann, 2015; Flanagan \& Hancock, 2010), it is used here to indicate socially disadvantaged populations. The invisibility or under-representation of such populations from health research means that policy and service provision tend not to take account of the obstacles to health they encounter. Indeed, these are often the populations with the greatest health needs, caused, for instance, by low levels of income, poor housing, education, or experiences of racism (Marmot, 2004). One important consequence for health policy and provision is that culturally inappropriate interventions may be developed which not only fail to improve access to healthcare for marginalized populations, but further compound health inequalities (Bonevski et al., 2014).

Experiences of social marginalization can generate suspicion and mistrust of researchers, including a fear that involvement may result in exploitation, mistreatment, or further stigma (Bonevski et al., 2014, p. 13). Inequalities such as those of age, gender, or ethnicity, resulting for instance in low levels of literacy, can further increase the difficulties of reaching specific sections of hard-to-reach populations, such as migrant mothers, for research purposes (Riggs et al., 2014). Gatekeepers might restrict access, perhaps to protect the more vulnerable members of their communities, or perhaps instead because they prefer to steer researchers towards community leaders (Ellard-Gray et al., 2015; 
Reeves, 2010). The pressures of coping with the demands of daily life may simply make research participation too costly for some.

A recent systematic review of research strategies for recruiting hard-to-reach participants notes the importance of developing creative approaches which prioritize community engagement (Bonevski et al., 2014) . This review found that collaborating with community organizations over research has been identified as crucial for building trust (Bonevski et al., 2014, p. 3; see also Flanagan \& Hancock, 2010). This study also notes the value of employing small scale, targeted qualitative research methods, to facilitate both the development of trust and depth of understanding (Bonevski et al., 2014, p. 19). Holistic, research intensive strategies, which rely on face-to-face interactions and emphasize the responsiveness of researchers to the needs of the target population, although costly in terms of time and money, are most likely to access hard-to-reach participants (Shaghaghi et al., 2011, p. 91). Recruiting such populations depends on the development of culturally tailored research materials; the employment of translators or bilingual research staff; making gifts or offering incentives for participation; being flexible about the timing and location of research; and emphasizing the lasting value of participation for the community or population in question (Bonevski et al., 2014).

A recent pilot study carried out in Belfast aimed to explore Roma women's attitudes to health during pregnancy. What follows will outline the health inequalities experienced by this migrant population in Northern Ireland, before describing the simultaneous dramaturgy method adopted for this purpose, and the responses it generated from participants. The efficacy of this arts-based approach for creatively engaging Roma participants will finally be evaluated.

\section{Context: Roma in Northern Ireland}

Engaging with minority groups on healthcare issues is important if the full range of human capabilities are to flourish (Nussbaum, 2011). One such minority group is Roma people who live worldwide and 
are Europe's largest and the most marginalized ethnic minority (Stojanovski, Janevic, Kasapinov, Stamenkovic, \& Jankovic, 2017). According to the European Commission in 2010, it has been estimated that there are between 10 and 15 million Roma people across Europe. The Roma community is the largest minority group in South-Eastern Europe since they started the migration from India over 1,000 years ago (Crowe \& Mazal Holocaust Collection, 1994). Despite the long-term inhabitation of Europe, socioeconomic status, education levels and health of Roma people are often below the population standards (Carrasco-Garrido, López de Andrés, Hernández Barrera, Jiménez-Trujillo, \& Jiménez-García, 2010; Stanković et al., 2016).

Existing health inequalities among Roma have recently been documented, particularly in relation to pregnancies, which show a higher rate of low-birth weight, preterm birth and infant mortality (Stanković et al., 2016). Unsurprisingly, access to ante-natal care amongst Roma women is generally low in comparison to non-Roma women, which is likely associated with the higher incidence of pregnancy complications in Roma women (Šegregur \& Šegregur, 2017). In addition, obesity rates tend to be higher amongst Roma women (Dolinska, Kudlackova, \& Ginter, 2007), which is a risk factor for pregnancy complications such as gestational diabetes (Catalano et al., 2012) and pre-eclampsia (Hyperglycemia and Adverse Pregnancy Outcome Study Cooperative Research Group, 2010). While efforts to combat the disproportionate incidence of pregnancy complications for Roma women might be regarded as a form of 'disease mongering', spreading fear of risk to health in the service of social control (Heath, 2006), it seems to us that participatory, non-didactic arts-based approaches to empowering disadvantaged populations to better understand their reproductive health and access support is instead an important way of prioritizing human dignity and flourishing, in the effort to reduce health inequalities (Nussbaum, 1995). This is distinct from the community action model of promoting better health, since it acknowledges unequal power within communities, particularly in the form of gender (Fuertes, Pasarín, Borrell, Artazcoz, \& Díez, 2012; Hennessey Lavery et al., 2005; Racher \& Annis, 2008). It is instead compatible with contemporary effort to develop a 'person-centred' 
approach to healthcare in UK policy and practice, which prioritizes human dignity over the achievement of targets or other institutional goals (Health Foundation, 2014).

In Northern Ireland, where this pilot study was conducted, Roma people started to arrive in 2007. The number of Roma people is not accurately known, however it is estimated that there are approximately 1,500 Romanian Roma and 500 Hungarian and Slovakian Roma living in Belfast (ISSA, 2016). Similar to other countries, Roma people tend to have low levels of literacy and experience unemployment, poor accommodation, low levels of engagement and discrimination. There is also poor access to health services, lack of involvement in decision making and poor coordination of services (ISSA, 2016). The possible reasons for disengagement of this community include the lack of understanding of Roma culture among the wider population in Northern Ireland, and discrimination. Our study, which was conducted in the Romanian Roma Community Association in Belfast, tested an arts-based method as a first contact effort to engage with local Roma women in discussion about healthcare and pregnancy.

\section{Method: simultaneous dramaturgy}

The method employed drew on Augusto Boal's Theatre of the Oppressed (1979), a style of theatre initially used in radical popular educational movements and developed in collaboration with underprivileged communities in Brazil and other Latin American countries, to empower hard-to-reach populations who are variously disadvantaged by class, gender or racial hierarchies. The empowerment involves a process of incremental transformation from a passive spectator, who is objectified in social hierarchies and state discourse, into an actor, or, more specifically, what Boal termed a 'spectactor', who can express the problems they face in theatrical form and work towards solutions that can be implemented in practical terms in their daily lives. The transformation involves four stages, the first two of which, 'knowing the body' and 'making the body expressive', focus on physicalization, through exercises and games designed to ease the participants into the creative artistic process. The emphasis on embodiment is particularly useful where there are initial difficulties with language and verbal 
comprehension, and the games help those unfamiliar with theatre and performance build to more complex forms of playing in terms of character, plot and scenario. The third stage, 'Theatre as language' is composed of three 'degrees', involving incremental development of complex scenariobased performance. The first degree is 'simultaneous dramaturgy', where actors or facilitators improvise a scenario with the help of a prepared script, with junctures designed to facilitate spectator intervention to suggestion solutions to key issues and change how the story unfolds. The second degree, 'image theatre', involves spectators intervening directly by changing the position of the actors' bodies to make images. The third degree is 'forum theatre', where spectators intervene in the scenario by acting. The fourth stage in Boal's approach is 'theatre as discourse', where the spectator as actor creates simple scenes or 'spectacles' according to their needs, to highlight particular themes or rehearse specific actions.

In this pilot engagement with Roma people, we relied on a modified version of simultaneous dramaturgy for the playful dimension of the theatrical style. Consistent with Freire's (1972) model of dialogic and problem-driven education as a tool for overcoming oppression, this approach was intended to reassure and engage participants through a less intrusive form of interaction than a research interview, since time and language barriers limited the ability to transform participants into 'spectactors'. Two scenarios were devised and a script was prepared which included junctures where sensitive issues such as diabetes, weight, and eating habits could be discussed in a relaxed and supportive environment. The research team played the scripted parts, with the help of a translator, recruited by the research team from a University-approved agency.

\section{Evaluation}

This pilot, based on a first contact engagement with this hard-to-reach population, focused on the essential aspects of simultaneous dramaturgy. This proved effective, even though the activity was 
heavily reliant on both a professional translator and the English language competency of one of the participants.

Considerable difficulties were encountered with the strategy adopted to recruit participants for the planned event. While invitation and information documents were translated and disseminated, both through the Romanian Roma Community Centre in Belfast and by distributing flyers in person on nearby streets where there is a concentration of Roma residents, no-one arrived at the advertised time. The advertised venue, a University theatre, was not a place frequented by Roma people. Reflecting on this, the team decided to cancel the planned event and visit the community centre in person, offering the pizzas and drinks bought for the event in return for an opportunity to present and discuss the research. A small number of available people agreed to discuss the project and consider becoming involved. Those who came to meet us, namely one young woman, her husband and toddler, and another young man, asked searching questions and the team explained that the purpose of the study was to begin testing a method that aimed to help Roma families with health issues in pregnancy in the longer term. We explained that we wanted to stage a theatre event, and after further questioning about our credentials and intentions, the young woman offered to bring her friends, if we could rearrange the event for a few days ahead. The men were not interested in being involved. We re-scheduled at a time that was convenient for participants and returned the following Monday, again bringing food and drink in return for their involvement.

Three women participated in the re-scheduled event, which took place in the community centre rather than the university theatre. This location was familiar and comfortable for participants, unlike the environment of the university. While this is a very small number, the team were nevertheless able to gather research material which was both illuminating, given the lack of research on this population, and valuable as an exploratory first step in developing a full-scale study. 
Of the three participants, one was non-English speaking and illiterate, one was non-English speaking and literate in her own language, and one was English speaking and literate. This caused problems when we asked them to sign consent forms. Audio recording verbal consent would have been preferable for this reason. One participant spoke English, which proved very helpful since the scarcity of Romani speakers meant that we had to work instead with a Romanian translator. This created some confusion and hilarity, for instance when 'placenta' was translated as 'polenta', so the ability of one of the participants to help clear up this and similar confusions was very helpful, and indicated a high degree of goodwill towards the research team. The recruitment process observed the principle of justice at the heart of research ethics, particularly by respecting the autonomy of research participants (Economic and Social Research Council, 2015:4). Despite the general lack of initial interest in the project and difficulties with translation, the co-operative, face-to-face, and flexible recruitment strategy resulted in securing informed consent from participants, through both the initial information meeting and the continuous open discussion of the research before, during and after the simultaneous dramaturgy. Participants continued to raise questions about the research, as well as about women's health in pregnancy. The team made every effort, with the help of the translator, to ensure that participants were aware that they were under no obligation to discuss their experiences of or attitudes to health pregnancy with us, and could withdraw at any time without consequences of any kind.

Participants demonstrated empathy for the challenges faced by scenario characters during pregnancy, and asked for explanations of technical medical language. They often interrupted script readings to comment and explain their own experiences. They took photos during the event, indicating that we were welcome, and thanked us at the end. They commented that they found the event worthwhile overall and were especially grateful for an explanation of how insulin works and how diabetes might be dangerous for a baby during pregnancy. They also said they would like our help to learn English and discover more about health in pregnancy. 
The participatory form of this research event suggested Roma orientations towards health in pregnancy, which in some ways are at odds with contemporary health promotion messages. Firstly, eating for two and putting on weight during pregnancy seems to be regarded as important, and not being able to eat or gain weight, whether because of nausea or other reasons, appears to be frowned upon: 'It's good if you put weight on, it's good for the child'. Exercising during pregnancy also seemed not to be expected. Instead, 'many sleep when they are pregnant'. While women might get exercise by doing housework, otherwise they rest because, as one participant explained, 'when you're pregnant you feel heavy, [...] you feel as if you have something on your back [and] heavy feet.'

Participants indicated that they had no experience of health education during pregnancy, apart from standard ante-natal education about giving birth. The event partly focused on the extent to which participants understood the causes and management of gestational diabetes, and it became clear that this was very limited. One participant recalled a friend who was diagnosed with gestational diabetes, but treated it as a normal part of pregnancy which would go away after the birth. While she was exceptionally tired during the pregnancy, she did not check her blood sugars regularly or try and regulate her diet, because she thought it was relatively normal.

\section{Future Plans}

We plan to carry out a full-scale study of Roma attitudes to health in pregnancy using the Boal's dramaturgy, outlined above. Funding has been secured to develop this work in collaboration with the Community Development and Personal and Public Involvement team at the Belfast Health and Social Care Trust, and the methodology will also be tested in Serbia, where there is the highest proportion of Roma outside of EU. This longer-term study, where trust has been more firmly embedded, will allow this specific technique to be more fully developed to incorporate Boal's first two stages, as well as 
expanding the third stage beyond simultaneous dramaturgy. This may include participants intervening directly in the dramatic action by acting themselves.

\section{Conclusions}

The modified version of simultaneous dramaturgy which was employed here proved to be helpful for accessing a hard-to-reach population, despite low levels of literacy, high language barriers, and cultural separateness. The recruitment of what may seem like a very small number was testament to intensive efforts to engage participants through repeated communication with Romanian Roma Community Association employees and face-to-face interactions which emphasized the aim of improving healthcare for Roma families. Bringing food and drinks as incentives and being flexible about the timing and location of the event, were also crucial in making the event possible at all and can be built upon in further development of this work.

The approach suggested attitudes to health in pregnancy which are in some important ways opposite to health promotion messages, including the continued value attached to the idea of eating for two in pregnancy, and getting plenty of rest rather than exercise. The disjuncture between the general promotion of healthy eating, limited weight gain and exercise in pregnancy, and the norms informing this small group of migrant Roma women about the value of gaining weight and resting during pregnancy, was revealed. A full-scale investigation of how widely held these attitudes are seems warranted. The apparent lack of understanding of risks posed by gestational diabetes to infant and maternal health reinforces health inequalities may present a significant challenge for those seeking to improve the health of hard-to-reach populations such as this one.

Participatory arts can open up forums for debate, discussion and reasoning, not only between researchers and hard-to-reach populations, but among participants themselves, in ways that might be carried over into other institutional contexts, such as in families and health-care settings. This 
engagement in practical reasoning, identified by Nussbaum as a basic human capability (Nussbaum, Glover, \& World Institute for Development Economics Research, 1995), prioritizes the human capacity for meaning making and agency. Any occasion which provokes reflection on and re-evaluation of normative expectations, for example of pregnant women, in the light of new information about how the human body copes with pregnancy, builds practical reasoning capabilities. Boal's dramaturgy promises a very different route to improving health in this way, in contrast with community-based or didactic approaches. While the former approach is indifferent to internal community inequalities such as gender, the latter tends to involve exerting pressure on individuals, often by evoking guilt or shame about their behaviours and bodies, in an effort to urge people to act differently and so meet general health targets (Buchanan, 2000). In keeping with the logic of Boal's model, the dramaturgy itself prompts participant reflection, rather than researchers seeking to persuade through didactic or other methods. The limited results of this pilot do raise important questions about the reliance of public health initiatives on utilitarian and behaviourist assumptions about human action, which take little account of the normative landscape within which lives play out. This can be explored more fully in advancing this dramaturgical approach for improving health in hard-to-reach populations.

\section{References}

Boag-Munroe, G., \& Evangelou, M. (2012). From hard to reach to how to reach: A systematic review of the literature on hard-to-reach families. Research Papers in Education, 27(2), 209-239. doi: 10.1080/02671522.2010.509515

Boal, A. (1979). Theatre of the Oppressed. London: Pluto.

Bonevski, B., Randell, M., Paul, C., Chapman, K., Twyman, L., Bryant, J., ... Hughes, C. (2014). Reaching the hard-to-reach: a systematic review of strategies for improving health and medical research with socially disadvantaged groups. BMC Medical Research Methodology, 14, 42-42. doi: 10.1186/1471-2288-14-42

Buchanan, D. R. (2000). An Ethic for Health Promotion: Rethinking the Sources of Human Well-Being. New York: Oxford University Press.

Carrasco-Garrido, P., López de Andrés, A., Hernández Barrera, V., Jiménez-Trujillo, I., \& JiménezGarcía, R. (2010). Health status of Roma women in Spain. The European Journal of Public Health, 21(6), 793-798. doi: 10.1093/eurpub/ckq153

Catalano, P. M., Mclntyre, H. D., Cruickshank, J. K., McCance, D. R., Dyer, A. R., Metzger, B. E., . . . Hadden, D. R. (2012). The hyperglycemia and adverse pregnancy outcome study. Diabetes care, 35(4), 780-786. doi: 10.2337/dc11-1790

Crowe, D., \& Mazal Holocaust Collection. (1994). A History of the Gypsies of Eastern Europe and Russia. London: St Martin's Press. 
Dolinska, S., Kudlackova, M., \& Ginter, E. (2007). The prevalence of female obesity in the world and in the Slovak Gypsy women. Bratislavske lekarske listy, 108(4-5), 207-211. doi: -

Economic and Social Research Council. (2015). Framework for Research Ethics. Retrieved from http://www.esrc.ac.uk/files/funding/guidance-for-applicants/esrc-framework-for-researchethics-2015/

Ellard-Gray, A., Jeffrey, N. K., Choubak, M., \& Crann, S. E. (2015). Finding the Hidden Participant. International Journal of Qualitative Methods, 14(5), 1-10. doi: 10.1177/1609406915621420

Flanagan, S. M., \& Hancock, B. (2010). 'Reaching the hard to reach' - lessons learned from the VCS (voluntary and community Sector). A qualitative study. BMC Health Services Research, 10, 92-92. doi: 10.1186/1472-6963-10-92

Freire, P. (1972). Pedagogy of the Oppressed. Harmondsworth: Penguin.

Fuertes, C., Pasarín, M. I., Borrell, C., Artazcoz, L., \& Díez, È. (2012). Feasibility of a community action model oriented to reduce inequalities in health. Health policy, 107, 289-295. doi:

10.1016/j.healthpol.2012.06.001

Health Foundation. (2014). Person-centred care made simple. London: The Health Foundation.

Heath, I. (2006). Combating Disease Mongering: Daunting but Nonetheless Essential. PLoS Med, 3(4), e146. doi: https://doi.org/10.1371/journal.pmed.0030146

Hennessey Lavery, S., Smith, M. L., Esparza, A. A., Hrushow, A., Moore, M., \& Reed, D. F. (2005). The Community Action Model: A Community-Driven Model Designed to Address Disparities in Health. American Journal of Public Health(4), 611

Hyperglycemia and Adverse Pregnancy Outcome Study Cooperative Research Group. (2010). Hyperglycemia and Adverse Pregnancy Outcome (HAPO) Study: Preeclampsia. American Journal of Obstetrics and Gynecology, 202(3), 255.e251-255.e257. doi: 10.1016/j.ajog.2010.01.024

ISSA. (2016). Roma Empowerment and Support for Inclusion: Case Study. Belfast, Northern Ireland. Retrieved from https://www.issa.nl/sites/default/files/pdf/Publications/equity/Case\%20Study\%20Northern Ireland web.pdf

Marmot, M. G. (2004). The Status Syndrome: How Social Standing Affects our Health and Longevity (1st American ed.). New York: Times Books.

Nussbaum, M. C. (1995). Human Capabilities, Female Human Beings. In M. C. Nussbaum \& J. Glover (Eds.), Women, Culture, and Development: A Study of Human Capabilities (pp. 61-104). Oxford: Clarendon Press.

Nussbaum, M. C. (2011). Creating Capabilities: The Human Development Approach. Cambridge, Mass.: Belknap Press of Harvard University Press.

Nussbaum, M. C., Glover, J., \& World Institute for Development Economics Research. (1995). Women, Culture, and Development: A Study of Human Capabilities. Oxford: Oxford University Press.

Racher, F. E., \& Annis, R. C. (2008). Community Health Action Model: health promotion by the community. Res Theory Nurs Pract, 22(3), 182-191

Reeves, C. L. (2010). A difficult negotiation: fieldwork relations with gatekeepers. Qualitative Research, 10(3), 315-331. doi: 10.1177/1468794109360150

Riggs, E., Gussy, M., Gibbs, L., Gemert, C., Waters, E., \& Kilpatrick, N. (2014). Hard to reach communities or hard to access services? Migrant mothers' experiences of dental services. Australian Dental Journal, 59(2), 201-207. doi: doi:10.1111/adj.12171

Šegregur, J., \& Šegregur, D. (2017). Antenatal characteristics of Roma female population in Virovitica-Podravina County, Croatia. Slovenian Journal of Public Health, 56(1), 47-54. doi: 10.1515/sjph-2017-0007

Shaghaghi, A., Bhopal, R. S., \& Sheikh, A. (2011). Approaches to Recruiting 'Hard-To-Reach' Populations into Research: A Review of the Literature. Health Promotion Perspectives, 1(2), 86-94. doi: 10.5681/hpp.2011.009 
Stanković, S., Živić, S., Ignjatović, A., Stojanović, M., Bogdanović, D., Novak, S., . . Vesna, C. (2016). Comparison of weight and length at birth of non-Roma and Roma newborn in Serbia. International journal of public health, 61(1), 69-73. doi: 10.1007/s00038-015-0736-1

Stojanovski, K., Janevic, T., Kasapinov, B., Stamenkovic, Z., \& Jankovic, J. (2017). An Assessment of Romani Women's Autonomy and Timing of Pregnancy in Serbia and Macedonia. Maternal and Child Health Journal, 1-7. doi: 10.1007/s10995-017-2292-1 